\title{
Pirandello's Analogy: A Source for a Better Understanding of the Social Impact of Stroke
}

\author{
M.A.C. van Haaren ${ }^{a} \quad$ M. Lawrence ${ }^{e}$ P.H. Goossens ${ }^{c}$ B. van den Bossche ${ }^{d, f}$ \\ M.J.H. Wermer ${ }^{b}$ A.A. Kaptein ${ }^{a}$ \\ Departments of a Medical Psychology and ${ }^{b}$ Neurology, Leiden University Medical Center, ${ }^{\mathrm{C}}$ Rijnlands Rehabilitation \\ Center, and ${ }^{d}$ Pirandello Association, Leiden, The Netherlands; ${ }^{\mathrm{e}}$ Institute for Applied Health Research/ \\ School of Health, Glasgow Caledonian University, Glasgow, UK; ${ }^{\mathfrak{f}}$ Centro di Studi Italiani, KU Leuven, Belgium
}

\section{Key Words}

Stroke $\cdot$ Rehabilitation $\cdot$ Humanities $\cdot$ Narrative $\cdot$ Social participation - Behavior

\begin{abstract}
Background: Suffering a stroke has major implications for the patient. To understand human suffering, one should understand society. Pirandello described society as a higher entity than the individual, thereby justifying human adaptability to society. We explore a qualitative finding that suggests that social trends may influence how stroke patients prioritize aspects of their rehabilitation. Methods: We compare a contemporary patient's experience of stroke recovery with that of a fictional character from the works of Luigi Pirandello. Both patients had two main residual symptoms: hemiparesis and aphasia. Results: The rehabilitation priorities of the two patients differed, and appeared to reflect the contemporaneous demands of society. Mobility was prioritized in 1910; communication was prioritized in 2010. However, essential aspects of 'being a stroke patient' remained unchanged; both patients retained a sense of self and both coped emotionally by being hopeful. Conclusions: We conclude that stroke patients respond to society's contempora-
\end{abstract}

\section{KARGER}

Fax +4161306 1234 E-Mail karger@karger.ch www.karger.com
(C) 2012 S. Karger AG, Basel 0014-3022/12/0672-0092\$38.00/0

Accessible online at:

www.karger.com/ene neous demands and expectations. Currently, society demands participation in a large social environment and this is reflected in stroke patients' priorities. This analogy could enable medical professionals to better understand the social impact of stroke, and consequently offer appropriate interventions to improve rehabilitation outcomes for individual patients.

Copyright $\odot 2012$ S. Karger AG, Basel

\section{Introduction}

Stroke has a withering impact on individuals as a common and long-term condition.

The narrative of stroke patients is an interesting source for modern literature. In novels, stroke may function as an enforcer of change in the sense of self, i.e. the individual's experience of continuity and unity. In this paper, we compare the narratives of two people affected by stroke. One, Cristoforo, is the central character in a novel published in 1906 [1]; the other is a patient, living with stroke in 2010.

Pirandello described society as being a higher entity than the individual (fig. 1). From this hierarchical per-

M.A.C. van Haaren

Department of Medical Psychology, Leiden University Medical Center (LUMC)

PO Box 9600

NL-2300 RC Leiden (The Netherlands)

Tel. +31 641777 418, E-Mail m.a.c.van.haaren@umail.leidenuniv.nl 


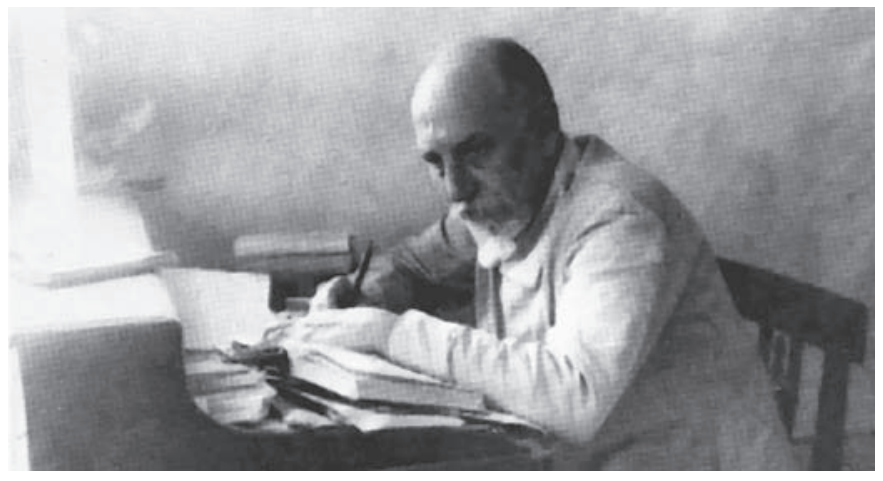

Fig. 1. Luigi Pirandello (1867-1936). Pirandello was awarded the Nobel Prize for literature in 1934.

spective it is understood that human individuals strive to adjust to the demands and expectations of society. The question we pose, and aim to answer, in this paper is: do social trends influence how stroke patients prioritize aspects of their rehabilitation?

\section{Methods}

We recruited a stroke patient to take part in an extended interview. Our selection criteria were the presence of two principal residual symptoms: right hemiparesis and aphasia. Importantly, the aphasia could not be severe otherwise the patient would not have been able to tolerate the lengthy conversation required to explore her narrative. Furthermore, the patient had to have been in recovery for some time after the stroke in order to be able to reflect on the recovery process and draw conclusions from it. We conducted a 3-hour interview with a 43-year-old stroke patient, Mrs. K., 2 years after her intracerebral hemorrhage. The intracerebral hemorrhage was caused by an arteriovenous malformation in the basal nucleus area on the left side, with an extension of the hemorrhage to the left frontal ventricle. Despite the severity of her intracerebral hemorrhage, Mrs. K. retained a good level of abstractness, mental flexibility and intellectual understanding (IQ $>100$ ). The interview was tape-recorded and was conducted in the patient's home. The interview schedule was divided into three parts: the patient in society, the patient as an individual, and the role of the doctor.

We selected the literature of Luigi Pirandello, in particular the short story 'La Toccatina' (1906) (literally, 'The Light Touch'), as the source for our literary narrative [1]. 'La Toccatina' - a metaphoric title - was the stroke which changed Cristoforo Golisch's life. The problem of identity is a central concern of Pirandello's oeuvre. In many of his works his characters' experiences reveal to them that they cannot have a fixed identity; an individual's identity depends on how others see them, and how they perceive others as seeing them. Diseases, such as stroke, serve to reinforce the concept of the fragility of the unified self.

Pirandello's Analogy: The Social Impact of Stroke

\section{Results}

\section{Patient in Society}

When comparing 'La Toccatina' to Mrs. K.'s narrative we detected striking differences in the priorities and associated goals of both of the patients. Cristoforo, a 48year-old man, lost his speech as well as his awareness of the right half of his body. Immediately following his stroke, Cristoforo focused on improving his mobility by kicking a lever to exercise his paralyzed muscles, and in recent times such early rehabilitation has been found to be highly effective [2]. In contrast, Mrs. K. revealed that, above all, she focused on restoring her communication skills. Both appeared to have the same residual symptoms, but they prioritized different rehabilitation needs and goals.

Mrs. K. found the communication group in the stroke patient union very helpful as a forum in which to discuss social struggles. In the communication group she felt free to practice her communication skills. In Cristoforo's narrative the importance of peer contact is similar. When he was able to walk, he asked his sister to take him to meet his friend Beniamino, who also had suffered a stroke. Cristoforo and Beniamino practiced their mobility skills, while Mrs. K. and the other stroke patients in the group worked on improving their communication skills.

Life adjustments are central both to Pirandello's work and to Mrs. K.'s narrative. According to Pirandello, the need for individuals to make adaptations derives from social pressure for the patient to change, or conform. The focus of contemporary society on communication is evident, with an ever-increasing trend towards high volumes of rapid communication using a range of media from speech and nonverbal expression to online social networking. Considered in this way, contemporary society stresses the need for individuals to communicate. In the interview, Mrs. K. indicated that society finds it difficult to respond to her 'invisible' impairment, aphasia:

'They (social environment) are able to cater for physical problems, but in case of communicating they are not.'

In addition, she stresses the current pressure for rapid communication. For example, when she went out to buy paracetamol, at the counter she could only recall the word 'aspirin'; the word 'paracetamol' did not come to her. After some minutes, a queue had built up behind her and the cashier became impatient. Society became impatient. 


\section{Patient as Individual}

Illness is truly an 'ontological assault', affecting our very being and not simply our activities [3]. This is certainly true of stroke. According to Pirandello, it is in the power of human adjustability to deal with this dissolution of the sense of self. Here, we define the sense of self as the experience of continuity and unity of the patient.

Immediately after the stroke, Mrs. K. experienced a strong feeling of loss of a sense of unity. She explained:

'I felt the half of my body had let me down.... I really have to address that body part.'

During recovery she not only improved physically but she also regained her sense of unity. In contrast, her sense of continuity was not restored, nor was it gone; it was changed. She explained that there was continuity before the stroke and a new kind of continuity in life after the stroke. She had made a new life plan.

Interestingly, Pirandello was familiar with this awareness of change in continuity:

'Suddenly he had become German, Cristoforo: in the meaning of a different man, because he never exactly was German.'

The only connection between Germany and Cristoforo was his parents; he had never even been to Germany. He experienced an interesting phenomenon called polyglottal aphasia [4]. Prior to his stroke, it seemed to Cristoforo that he had forgotten how to speak German. However, German, his mother tongue, had 'survived' the stroke attack, but the Italian language that he had learned in later life seemed to be lost. Pirandello used this metaphor to highlight Cristoforo's emergent and altered sense of continuity following the stroke. These examples demonstrate that Mrs. K. and Cristoforo responded to the ontological assault in very similar ways.

Mrs. K. coped with the enforced change in her life plan with hope. She expects the future to be positive in the sense of having a small job and taking an active part in society. Literature influenced her coping behavior. Her husband heard about the story of Dr. Jill Bolte Taylor [5]. He read her narrative to his wife, of the way Dr. Jill Bolte Taylor recovered 8 years after her stroke. Hope was verbalized when Mrs. K. said:

'It is just two years ago for me.'

Before Cristoforo suffered from a stroke, he met his old friend, Beniamino, shuffling through the streets of Rome. Beniamino, stammering and with eyelids which constantly were closing, did not resemble the friend Cristoforo had played pranks with as a youngster. The change in Beniamino made Cristoforo ill, and for weeks he spoke of nothing else.

'Really? he said. One light touch (mild stroke) and it is that far? No, goddamn, no! I won't let that happen. ... I'll shoot myself, I'll kill myself, for God's sake!'

One month later Cristoforo had a stroke. Rather than wanting to commit suicide, as he had thought he would, he was very pleased the first time he was able to move his hand slightly. He still could not move his leg, but he was full of hope that it would happen someday soon. Pirandello shows us the perception of those in the "notstroke world' about having a stroke, and how this opinion is changed when the same person enters 'the stroke world'.

\section{Doctors in Time}

A change was seen when comparing the role of the doctors in both stories. In 'La Toccatina' Pirandello describes a typical biomedical doctor:

'The doctor tried to give a scientific explanation to the symptoms. He stated the name of the disease: hemiparesis. He determined the treatment.'

This is almost the only time the doctor comes into play in 'La Toccatina'. Please note the lack of mention of aphasia in the doctor's diagnosis. For Pirandello, and most probably for other laymen as well, aphasia was just a result of the hemiparesis, which of course is a purely biomedical view. For Pirandello, the doctor represents positivism and its belief in science and rationality. However, Pirandello, together with other authors, was probably already disappointed about the possibilities of modern medicine in the late 19th century [6]. Therefore, he describes a doctor who does believe in science and rationality and yet fails to understand the patient. This could be seen as a metaphor for the failure of the scientific movement. The doctor 'rationalizes' the state of the patient and is completely unable to grasp the existential difficulties experienced by the patient. Half a century later, in response to an acknowledged 'need for a new medical model' [7], Engel theorized a model, his biopsychosocial model, which moved away from reductionism of a disease to its biomedical cause.

Mrs. K.'s doctor, a biopsychosocial doctor, told her she had two main residual symptoms, namely, hemiparesis and aphasia. In addition, she had few cognitive problems. Engel described how, in contrast to doctors who adopt a biomedical approach to diagnosis and treatment, biopsychosocial doctors are able to broaden the scope of the help 
they offer to patients. Their approach enables them to address biological, psychological and social factors, all of which play a significant role in human functioning in the context of illness. In addition, the biopsychosocial model acknowledges how symptoms or 'being ill' does imply not purely the disappearance of a function but a new condition for the whole patient, which is a suggestion previously made by Hughlings Jackson, about a hundred years ago [8].

However, Mrs. K. consulted her doctor only about biomedical problems; psychological and social problems were dealt with by her husband or her mother. She explained:

'You should see him (the doctor) only if you really need him.'

Mrs. K. has reduced the role of the doctor back to that of a biomedical doctor; she does not understand biopsychosocial practice as being a doctor's role.

\section{Discussion}

In conclusion, we compared the experiences of a fictional character from 1910 with those of a patient living with a stroke in 2010. Both were affected by stroke in similar ways, yet in 2010 patients' priorities differ from those of patients in 1910. Cristoforo and Mrs. K. regained a sense of unity while working on improving their motor and communication skills. Over time, for both, the experience of continuity was resolved to a new post-stroke continuity. With regards to emotional coping behavior, both patients stayed positive and full of hope, attitudes not usually understood by those in the 'not-stroke world'. Both patients displayed a response shift, the adjusting of internal norms or standards regarding quality of life in illness. This phenomenon is true for patients with, for example, cancer as well, who adjust the level at which they judge their quality of life over the course of their chemotherapy with all its major side effects $[9,10]$. Similarly in this case, both stroke patients adjusted their judgment of their quality of life levels during rehabilitation.

Narratives can be divided into three types as described by the sociologist Arthur Frank in 1995 [11]. Frank is particularly interested in patients from the 'remission society': these patients are unable to return to the status quo ante, as is the case for stroke patients [12]. The three types of patient narratives have been described, namely, restitution, chaos and quest. A typical quest narrative is that of Brodal, a professor in neuro- anatomy, who recounts his personal experience of stroke. In his systematically arranged case report he does not engage in vain restitution narratives nor does he allow himself to sink into chaos [13]. A more recent patient account provided by Bolte Taylor is typical of a restitution narrative [5]. In this narrative Bolte Taylor is diagnosed as having a serious illness, stroke. She struggles for some period of time against the illness with the help of proper healing authorities and in the end the struggle is successful. In contrast, Cristoforo's narrative is one of chaos; after the stroke he cannot make any sense of his current situation. The narrative of Mrs. K. is ongoing. In the beginning it appeared chaotic, as has been described by other stroke patients [14]. However, 2 years later Mrs. K.'s narrative more closely resembles that of Brodal: a quest narrative.

It is important to note that the perspective of the narrator, Pirandello, is that of a person who did not suffer a stroke himself. The author imagines what it would be like to suffer a stroke. At the same time, as pointed out by Bassanese, Pirandello's wife was known as a person with enduring confusion and the disability to bond with society due to mental illness [15]. This unfortunate circumstance may have helped Pirandello develop insight into the experience of suffering a stroke and its consequences.

Another important factor is the role of the doctor which Pirandello uses as a vehicle to convey his views on the contemporaneous scientific movement. Pirandello and his contemporaries appear to have been disappointed as the possibilities of modern medicine had not been realized [6]. This sense of disappointment is reflected in the French literature of the time, especially those tracts describing the struggles experienced by Jean-Martin Charcot as he attempted to identify the etiology of hysteria and hypnosis [6]. Similar confusion reigned regarding contemporary understanding of the etiology of stroke, as seen in the work of Adrien Proust [16], supervised by Charcot [17]. The etiology of stroke became clearer following the publication of the pathological work of Rokitansky and Virchow [18].

Pirandello's 'La Toccatina' was written and published in the so-called Interbellum: a period in 20th-century Europe when mechanization and rationalization of the production of goods was dominant. This implied that society attached great value to physical capabilities and skills in individuals. Pirandello explicitly describes this aspect of physical action and movement in Cristoforo's medical history during his rehabilitation. 
One hundred years separates the two stories. Today Pirandello's work continues to entertain, but does it still have a useful message for doctors in 2010? Take physical improvement: it is not necessary to look up 'La Toccatina' to determine the best treatment, but when a doctor is interested in the ontological being of a stroke patient he is certainly helped by Pirandello, whose philosophical message is that society is a higher entity than the individual, and therefore individuals have to adjust to society's norms. For Pirandello, this demonstrates the strength of human adaptability to existential problems. This idea is still relevant in 2010, as our comparison of 'La Toccatina' to the narrative of Mrs. K. demonstrates.

Society can be seen as a variable in the concept of human adaptability. Society certainly has changed in the last hundred years, particularly in recent decades with the rise of the internet and mobile communication technology. These communication media have extended the social environment of the individual. In addition, major differences in the way that health care systems were organized one hundred years ago and at present undoubtedly impact on the survival of patients with various illnesses, e.g. stroke. These differences reflect the importance that society attaches to objectives of medical care. It seems safe to state that in Pirandello's epoch, being able to move - again - after a stroke was a major objective of medical management and rehabilitation. At present, being able to move - again - remains a major goal of medical care. However, current developments in society emphasize communication and interaction to a great degree. This is reflected in our patient's narrative.

Even in the 21st century, (medical) care for patients with physical problems tends to focus on physical aspects, e.g. the use of physiotherapy to teach patients with a stroke to re-use their physical capacities again. However, modern journals in neurology and other medical subdisciplines make it clear that, increasingly, the so-called biopsychosocial model is likely to be adopted. In that model, medical (physical) management is complemented by psy- chological management, e.g. cognitive behavioral interventions and social interventions, e.g. patient organizations [7]. This shift in practice is reflected in the increasing tendency of social insurance systems for health care costs to also cover the costs associated with psychological and social interventions.

Nonetheless, the individual has remained unchanged, as demonstrated by the similar effect of stroke on the sense of self and on emotional intercourse in 1910 and in 2010. Both Cristoforo and Mrs. K. developed a new sense of continuity after stroke and revealed similarities in how they faced life after stroke, by being very positive and full of hope. The inner core of the individual did not change over time. The essence of being a stroke patient did not change - society did, thereby justifying the different priorities of patients in different contexts. Doctors may find useful the analysis presented here, as it aids a better understanding of patient needs. Patients will always be trying to respond to society's call, i.e. to respond to the demands and expectations of society. Currently, society demands participation in a large social environment and that is reflected in patient priorities. However, as society is constantly changing, doctors should be aware of and remain responsive to associated changes in patient priorities. Importantly, this analysis serves to provoke awareness of the impact society has on the individual and especially the patient, within a temporal context.

\section{Acknowledgments}

We would like to thank Mr. W. Fiederichs, director of the The Netherlands Pirandello association, for his help in the literature study. We are very grateful to an anonymous reviewer whose constructive comments helped us improve the paper.

\section{Disclosure Statement}

None.
References

Eur Neurol 2012;67:92-97
1 Pirandello L: La toccatina; in Pirandello L (ed): Novelle per un Anno. Milano, Collana I Meridiani, 1985, pp 112-136.

-2 Cumming TB, Thrift AG, Collier JM, Churilov L, Dewey HM, Donnan GA, Bernhardt J: Very early mobilization after stroke fasttracks return to walking: further results from the phase II AVERT randomized controlled trial. Stroke 2011;42:59-64.
-3 Pellegrino ED: Philosophy of medicine: problematic and potential. J Med Philos 1976;1:5-31.

-4 Sghirlanzoni A, Pareyson D: 'La toccatina': polyglottal aphasia in Pirandello. Ital J Neurol Sci 1997; 18:55-57.

5 Bolte Taylor J: My Stroke Insight: a Brain Scientist's Personal Journey. New York, Plume books, 2009. 
6 Koehler P: About medicine and the arts: Charcot and French literature at the fin-desiècle. J Hist Neurosci 2001;10:27-40.

7 Engel GL: The need for a new medical model: a challenge for biomedicine. Science 1977; 196:129-136.

8 Jackson JH: Remarks on dissolution of the nervous system as exemplified by certain post-epileptic conditions. Med Press Circular 1881;35:399-402.

9 Cupp J, Simmons Z, Berg A, Felgoise SH, Walsh SM, Stephens HE: Psychological health is maintained as physical function declines. Amyotr Lateral Sci 2011;12:290-296.
10 Donohoe JE: To what extent can response shift theory explain the variation in prostate cancer patients' reactions to treatment sideeffects? A review. Qual Life Res 2011;20:161167.

11 Frank A: The Wounded Story teller: Body, Illness, and Ethics. Chicago, University of Chicago Press, 1995.

12 Brody H: Types of stories about sickness; in Brody H (ed): Stories of Sickness. New York, Oxford University Press, 2003, pp 85-93.

13 Brodal A: Self-observations and neuro-anatomical considerations after a stroke. Brain 1973;96:675-694.

14 Hjelmblink F, Holmstrom I: To cope with uncertainty: stroke patients' use of temporal models in narratives. Scand J Caring Sci 2006;20:367-374.
15 Bassanese FA: The International Provincial; in: Understanding Luigi Pirandello. South Carolina, University of South Carolina Press, 1997, pp 1-22.

16 Proust A: Des Différentes Formes de Ramollissement du Cerveau. Paris, Asselin, successeur de Béchet Jeune et Labé, Librairie de la Faculté de Médecine, 1866.

17 Bogousslavsky J, Paciaroni M: Did JeanMartin Charcot contribute to stroke? Eur Neurol 2010;64:27-32.

18 Paciaroni M, Bogousslavsky J: How did stroke become of interest to neurologists? Neurology 2009;73:724-728. 